American Journal of Pharmaceutical Education 2017; 81 (1) Article 2.

\title{
VIEWPOINTS
}

\section{Why Every Aspect of an Academic Pharmacy Career Should Be Viewed Through the Lens of Scholarship}

Reza Mehvar, PharmD, PhD

Chapman University School of Pharmacy, Irvine, California

Attending the 2016 annual meeting of the American Association of Colleges of Pharmacy (AACP) in Anaheim, California, one could not help but notice that the general underlying theme in almost every activity and presentation was scholarship. Indeed, all of the four categories, ${ }^{1}$ scholarship of discovery, integration, application, and teaching, were prominently on display by the members of the academy. Research or scholarship of discovery has traditionally been the cornerstone of promotion and tenure decisions in academia, including in academic pharmacy. However, pharmacy faculty members, like their counterparts in other disciplines, increasingly rely on evidence and peer review, the two pillars of scholarship, in all aspects of their responsibilities, which besides research include teaching and service.

This is an exciting time to be in academic pharmacy because, despite some challenges, opportunities are abundant for evidence-based and peer-reviewed research, teaching/learning, and service. As for research, significant progress in recent years in chemistry, biology, pharmacogenomics, and bioinformatics has substantially increased opportunities for biomedical and pharmaceutical scientists within the academy to conduct exciting discovery and translational research, including development of personalized medicine. ${ }^{2,3}$ Although challenges remain with regard to recent declines in research funding, these challenges also have led to an increased level of collaboration and multidisciplinary research among the members of the academy both within pharmacy schools and with colleagues in other departments and schools. Indeed, AACP has been cultivating collaborative team research in academic pharmacy by offering a year-long Academic Research Fellows Program, which is intended to expand the leadership capabilities of pharmacy faculty members in the area of research.

The second area of opportunity for scholarship for pharmacy faculty members, which is the main focus of this viewpoint, is the scholarship of teaching and learning (SoTL). The scholarship of teaching and learning needs to be viewed through the same lens as the scholarship of discovery and translational research, which means it should have the same rigor in its design and implementation.
When viewed from a scientific lens, SoTL has the same elements as other scientific inquiries that faculty members use in their research. ${ }^{4}$ These elements include identification of a gap in teaching effectiveness, development of a hypothesis when appropriate, creation of an experimental design to test the hypothesis or assumptions made about the teaching strategy, and appropriate analysis of data. ${ }^{4}$ The subsequent dissemination of the findings through peerreviewed mechanisms is a necessary element of SoTL, which distinguishes it from scholarly teaching, with the latter lacking a formal peer-reviewed communication of the activity. ${ }^{5}$

Given the recent emphasis of the academy on active engagement of learners in their own learning and the advances in technology, there are many opportunities for scholarly teaching and SoTL in academic pharmacy. Indeed, as demonstrated by the many articles focused on SoTL that have been published in this and other journals, pharmacy faculty members are hard at work using evidencebased scholarly teaching and disseminating their work through peer-reviewed publications.

Although SoTL by pharmacy faculty members has dramatically advanced in recent years, application of rigorous standards of scholarship to teaching/learning has been rather slow. In 2004, an AACP task force was formed and charged with the development of standardized criteria for manuscripts submitted to the Journal for the category of Instructional Design and Assessment. The work of the task force was published in the Journal in the form of recommendations and guidelines for the design and reporting of manuscripts on SoTL. ${ }^{6}$ These guidelines improved the quality of SoTL manuscripts published in the Journal. However, most of the reports in this area still lacked rigor in the assessment part of SoTL because they relied mostly on qualitative data and perception of improved learning as opposed to solid performance data. Consequently, a second report of the task force was published in 2009 that emphasized the need for a more rigorous assessment of educational strategies in SoTL manuscripts to include evidence-based data to document improved learning. ${ }^{7}$ Collectively, these efforts have improved the quality of SoTL manuscripts published in the 


\section{American Journal of Pharmaceutical Education 2017; 81 (1) Article 2.}

Journal, and in particular, more and more published manuscripts are based on objective assessments of learning improvement. As expected, this trend is not limited to SoTL manuscripts published in the Journal; it extends to other journals that are dedicated to the advancement of SoTL in academic pharmacy.

Despite these improvements, the author believes the next target area for improvement of SoTL in pharmacy should be study design. As a pharmacy faculty member involved in both the scholarship of discovery/integration and SoTL, the author can attest to the inherently more challenging design of SoTL studies, compared with discovery or integration research. This is because rarely is a SoTL study designed separately from the confines of day-to-day teaching/learning activities that are normally occurring in schools and colleges of pharmacy. By contrast, most of the scholarships of discovery and integration lend themselves to randomized and/or crossover designs that may be planned specifically to test a hypothesis using in vitro, ex vivo, or in vivo methods in animals. Except for studies in specific patient populations, even non-educational research in humans poses fewer limitations, in most cases, than does SoTL. The most challenging aspect of SoTL designs is how to include proper controls and comparators if the study is conducted within the usual classroom settings, which appears to be the case for most SoTL articles related to novel instructional strategies published by pharmacy faculty members. In these cases, faculty members inevitably try to design studies without disadvantaging a group of students or causing significant disruption of day-to-day activities. Therefore, the tendency has been to use less than optimal controls and comparators such as the use of historical controls from the previous cohorts to document effectiveness of an intervention in a new cohort.

Here, I use the reports of the effectiveness of the flipped classroom, which has recently gained popularity in higher education, ${ }^{8}$ as an example of the difficulties in the design of SoTL. I conducted a search on the Journal's search engine alternately using the keywords "flipped," "flip," and "flipping" in the title field to retrieve articles related to the flipped classroom strategy in pharmacy. The search resulted in 10 articles, including one review ${ }^{8}$ and nine primary ${ }^{9-17}$ articles, all published between 2012 and 2016. A summary of the characteristics and outcomes of these studies are presented in Table 1. As demonstrated in this table, all but one study used quantitative performance data as a measure of improvement in learning, which is in line with the Journal's guidelines. ${ }^{7}$ However, all the performance studies used data from prior years for comparison, which may have contributed, at least in part, to the different results and conclusions regarding the effectiveness of the method (Table 1). This point was clearly demonstrated by Bossaer et al,${ }^{15}$ who showed that there was no difference in the examination grades between the flipped classroom and interactive lectures when no correction was made for the potential differences between the academic abilities of the two cohorts. However, when the examination grades were corrected for the academic performance of students in the pharmacy program, the grades for the cohort with the flipped classroom were significantly lower than those of the cohort with the interactive lectures (Table 1). Nevertheless, accounting for all the variables, some of them even unknown, would be very difficult using historical comparators. Alternatively, in recent years, some authors have advocated using design research or design experiments in educational research, which is based on pragmatic, iterative, real-world research and is substantially different from controlled studies. ${ }^{18,19}$ Because most faculty members who conduct SoTL studies in pharmacy are not experts in educational research, they are not familiar with the intricacies of educational research designs. Therefore, there is a need for more training of pharmacy faculty members on the proper design of educational research.

Although the scholarship of service has not received its proper recognition in academia, ${ }^{20}$ opportunities for scholarship are also abundant in the service component of a pharmacy faculty member, whether it is in the academic (including clinical practice), professional, or community area. Some types of scholarship of service fall into the broad category of SoTL, such as activities in the areas of curriculum development and program or curriculum assessment. Other types, such as scholarship of community engagement, are categorized within the scholarship of application, defined by Boyer. ${ }^{1}$ At any rate, faculty members should strive to view the service on any committee or task force or engagement in the community through the lens of scholarship.

On a personal note, having been a faculty member at three US schools/colleges of pharmacy (Drake University, Texas Tech University, and now Chapman University), I have been fortunate to have had the opportunity to engage in scholarship in all three areas - research, teaching, and service. This has been made possible not only by the support that I have received from my colleagues and the administrators at these institutions, but also by the peer-reviewed programs that AACP has implemented to encourage scholarship. The AACP's New Investigator Grant stimulated my discovery/integration research at Drake University. The Innovation in Teaching Awards that I received at Drake University and Texas Tech University pushed me forward in the area of scholarly teaching. Also, the Journal allowed me to move from scholarly 


\section{American Journal of Pharmaceutical Education 2017; 81 (1) Article 2.}

teaching to SoTL by peer-reviewing and disseminating most of my work in the area of SoTL. And now, I have the honor of being recognized by my peers as a recipient of the AACP Distinguished Teaching Scholar Award. Thank you colleagues and AACP for a rewarding career.

\section{REFERENCES}

1. Boyer EL. Scholarship Reconsidered: Priorities of the Professoriate. New York, NY: John Wiley \& Sons; 1990.

2. Tucker G, DeSilva B, Dressman J, et al. Current challenges and potential opportunities for the pharmaceutical sciences to make global impact: an FIP perspective. J Pharm Sci. 2016;105(9):24892497.

3. Vicini P, Fields O, Lai E, et al. Precision medicine in the age of big data: the present and future role of large-scale unbiased sequencing in drug discovery and development. Clin Pharmacol Ther. 2016;99 (2):198-207.

4. DiPiro JT. Good teaching is good science. Am J Pharm Educ. 2007;71(1):Article 10.

5. Richlin L. Scholarly teaching and the scholarship of teaching. New Dir Teach and Learn. 2001;86:57-68.

6. Poirier T, Crouch M, Hak E, MacKinnon G, Mehvar R, MonkTutor M. Guidelines for manuscripts describing instructional design or assessment: the IDEAS format. Am J Pharm Educ. 2004;68(4): Article 92.

7. Poirier T, Crouch M, MacKinnon G, Mehvar R, Monk-Tutor M. Updated guidelines for manuscripts describing instructional design and assessment: the IDEAS format. Am J Pharm Educ. 2009;73(3): Article 55.

8. Rotellar C, Cain J. Research, perspectives, and recommendations on implementing the flipped classroom. Am J Pharm Educ. 2016;80 (2):Article 34.
9. Pierce R, Fox J. Vodcasts and active-learning exercises in a "flipped classroom" model of a renal pharmacotherapy module. Am J Pharm Educ. 2012;76(10):Article 196.

10. McLaughlin JE, Griffin LM, Esserman DA, et al. Pharmacy student engagement, performance, and perception in a flipped satellite classroom. Am J Pharm Educ. 2013;77(9):Article 196. 11. Persky AM, Dupuis RE. An eight-year retrospective study in "flipped" pharmacokinetics courses. Am J Pharm Educ. 2014;78(10): Article190.

12. Wong TH, Ip EJ, Lopes I, Rajagopalan V. Pharmacy students' performance and perceptions in a flipped teaching pilot on cardiac arrhythmias. Am J Pharm Educ. 2014;78(10):Article 185. 13. Khanova J, McLaughlin JE, Rhoney DH, Roth MT, Harris S. Student perceptions of a flipped pharmacotherapy course. Am J Pharm Educ. 2015;79(9):Article 140.

14. Munson A, Pierce R. Flipping content to improve student examination performance in a pharmacogenomics course. Am J Pharm Educ. 2015;79(7):Article 103.

15. Bossaer JB, Panus P, Stewart DW, Hagemeier NE, George J. Student performance in a pharmacotherapy oncology module before and after flipping the classroom. Am J Pharm Educ. 2016;80(2):Article 31. 16. Giuliano CA, Moser LR. Evaluation of a flipped drug literature evaluation course. Am J Pharm Educ. 2016;80(4):Article 66.

17. Koo CL, Demps EL, Farris C, Bowman JD, Panahi L, Boyle P. Impact of flipped classroom design on student performance and perceptions in a pharmacotherapy course. Am J Pharm Educ. 2016;80 (2): Article 33.

18. Cobb P, Confrey J, diSessa A, Lehrer R, Schauble L. Design experiments in educational research. Educ Res. 2003;32(1):9-13. 19. Collins A, Joseph D, Bielaczyc K. Design research: theoretical and methodological issues. J Learn Sci. 2004;13(1):15-42.

20. Brazeau GA. Revisiting faculty service roles - is "faculty service" a victim of the middle child syndrome? Am J Pharm Educ. 2003;67(3):Article 85. 